\title{
Next-Generation Sequencing-Based Quantitative Detection of Hepatitis B Virus Pre-S Mutants in Plasma Predicts Hepatocellular Carcinoma Recurrence
}

\author{
Chiao-Fang Teng 1,2,3,*(D), Tsai-Chung Li ${ }^{4,5} \mathbb{D}$, Hsi-Yuan Huang ${ }^{6}$, Jia-Hui Lin ${ }^{1}$, Wen-Shu Chen ${ }^{2}$, \\ Woei-Cherng Shyu ${ }^{1,7,8,9}$, Han-Chieh Wu ${ }^{10}\left(\mathbb{D}\right.$, Cheng-Yuan Peng ${ }^{11,12} \mathbb{D}$, Ih-Jen Su ${ }^{13, *}$ and \\ Long-Bin Jeng ${ }^{2, *}$
}

1 Graduate Institute of Biomedical Sciences, China Medical University, No.91, Hsueh-Shih Rd., Northern Dist., Taichung City 404, Taiwan; estherlin292@gmail.com (J.-H.L.); shyu9423@gmail.com (W.-C.S.)

2 Organ Transplantation Center, China Medical University Hospital, No.2, Yude Rd., Northern Dist., Taichung City 404, Taiwan; d00443003@gmail.com

3 Research Center for Cancer Biology, China Medical University, Taichung City 404, Taiwan

4 Department of Public Health, College of Public Health, China Medical University, Taichung City 404, Taiwan; tcli@mail.cmu.edu.tw

5 Department of Healthcare Administration, College of Medical and Health Science, Asia University, Taichung City 413, Taiwan

6 Department of Laboratory Medicine, China Medical University Hospital, Taichung City 404, Taiwan; cn0312@gmail.com

7 Department of Occupational Therapy, Asia University, Taichung City 413, Taiwan

8 Department of Neurology, China Medical University Hospital, Taichung City 404, Taiwan

9 Translational Medicine Research Center, China Medical University Hospital, Taichung City 404, Taiwan

10 National Institute of Infectious Diseases and Vaccinology, National Health Research Institutes, Zhunan 350, Taiwan; hanjie@nhri.org.tw

11 Division of Hepatogastroenterology, Department of Internal Medicine, China Medical University Hospital, Taichung City 404, Taiwan; cypeng@mail.cmuh.org.tw

12 School of Medicine, China Medical University, Taichung City 404, Taiwan

13 Department of Biotechnology, Southern Taiwan University of Science and Technology, No.1, Nantai St., Yongkang Dist., Tainan City 710, Taiwan

* Correspondence: chiaofangteng@gmail.com (C.-F.T.); suihjen0704@stust.edu.tw (I.-J.S.); longbin.cmuh@gmail.com (L.-B.J.); Tel.: +886-4-2205-2121 (C.-F.T.); +886-6-253-3131 (I.-J.S.); +886-4-2205-2121 (L.-B.J.); Fax: +886-4-2202-9083 (C.-F.T.); +886-6-242-5747 (I.-J.S.); +886-4-2202-9083 (L.-B.J.)

Received: 12 June 2020; Accepted: 23 July 2020; Published: 24 July 2020

\begin{abstract}
Hepatocellular carcinoma (HCC) is among the most common and lethal human cancers worldwide. Despite curative resection, high recurrence of HCC remains a big threat, leading to poor patient outcomes. Hepatitis B virus (HBV) pre-S mutants, which harbor deletions over pre-S1 and pre-S2 gene segments of large surface proteins, have been implicated in HCC recurrence. Therefore, a reliable approach for detection of pre-S mutants is urgently needed for predicting HCC recurrence to improve patient survival. In this study, we used a next-generation sequencing (NGS)-based platform for quantitative detection of pre-S mutants in the plasma of HBV-related HCC patients and evaluated their prognostic values in HCC recurrence. We demonstrated that the presence of deletions spanning the pre-S2 gene segment and the high percentage of pre-S2 plus pre-S1 + pre-S2 deletions, either alone or in combination, was significantly and independently associated with poor recurrence-free survival and had greater prognostic performance than other clinicopathological and viral factors in predicting HCC recurrence. Our data suggest that the NGS-based quantitative detection of pre-S mutants in plasma represents a promising approach for identifying patients at high risk for HBV-related HCC recurrence after surgical resection in a noninvasive manner.
\end{abstract}


Keywords: hepatocellular carcinoma; hepatitis B virus; pre-S mutants; recurrence; next-generation sequencing

\section{Introduction}

Hepatocellular carcinoma (HCC) is the sixth most frequent human cancer and the second leading cause of cancer-related death worldwide, responsible for around 740,000 deaths in 2012 [1-3]. Many therapeutic strategies have been developed for the treatment of HCC, among which surgical resection is regarded as one of the best therapeutic options for HCC patients [4-7]. However, the recurrence rate of HCC after curative surgical resection is up to $80 \%$ within five years, leading to a poor patient survival rate as low as 30\% within five years [8-10]. Therefore, identification of effective and reliable biomarkers for the prediction of HCC recurrence after surgical resection is urgently needed, allowing for earlier and better prevention and management of the recurrent HCC to improve patient survival.

Chronic infection with hepatitis B virus (HBV) is a major risk factor for HCC development, accounting for over $50 \%$ of total HCC cases in developing countries [11,12]. Over the past decade, we have identified ground glass hepatocytes (GGHs) in liver tissues as a histological marker of chronic HBV infection as well as the preneoplastic lesions of HBV-associated HCC [13]. Two different types of GGHs (designated types I and II) consistently express distinct inclusion-like and marginal patterns of pre-S mutant proteins (pre-S1 and pre-S2 mutants), which contain deletion mutations over the pre-S1 and pre-S2 gene segments of HBV large surface proteins, respectively [14,15]. We have well demonstrated that both types of pre-S mutants are accumulated in the endoplasmic reticulum (ER) of hepatocytes in patients with chronic HBV infections and can induce multiple ER stress-dependent and -independent signal pathways, resulting in genomic instability and growth advantages of hepatocytes and eventually HCC formation [13,16,17]. The prevalence of pre-S mutants in liver tissues and serum/plasma samples of chronic HBV carriers is approximately $37 \%$, and is gradually increased with disease progression, and eventually accounts for up to $60 \%$ in HCC patients $[13,18]$. The presence of pre-S mutants in chronic HBV carriers confers a 5-fold higher risk for HCC development [18-20]. Moreover, HBV-related HCC patients carrying pre-S mutants have a significantly greater risk of HCC recurrence after surgical resection, even after receiving postoperative antiviral therapy [21-24]. As a result, the presence of pre-S mutants represents an important high-risk biomarker for HCC development in chronic HBV carriers as well as HCC recurrence in HBV-related HCC patients following surgical resection.

Three major approaches have been successfully applied to detect pre-S mutants in liver tissues or serum/plasma samples for identifying patients with high risk of HCC development and recurrence, one based on the immunohistochemistry staining of HBV surface antigens (HBsAg; surface proteins) for GGHs visualization [15,22], one utilizing polymerase chain reaction (PCR) amplification of pre-S gene for DNA sequencing [19-21], and the usage of the Pre-S Gene Chip for hybridization with pre-S gene PCR products $[18,24]$. However, these approaches provide only qualitative and semi-quantitative detection results and remain in need of improvement. Therefore, we have recently developed a next-generation sequencing (NGS)-based platform for quantitative detection of pre-S mutants in plasma samples of HBV-related HCC patients with better sensitivity and accuracy $[25,26]$. In this study, we further evaluated this NGS-based quantitative detection of pre-S mutants as a powerful approach to predict HCC recurrence in HBV-related HCC patients receiving surgical resection. 


\section{Materials and Methods}

\subsection{Human Sample Collection}

In this study, to investigate the association of preoperative pre-S deletions with median overall survival (OS) and recurrence-free survival (RFS), the plasma samples were obtained retrospectively from 75 HBV-related HCC patients on the day of the surgical resection they received at China Medical University Hospital (Taichung, Taiwan) from March 2004 to September 2016, under the approval of the China Medical University and Hospital Research Ethics Committee (protocol no. CMUH106-REC2-110) and were stored at $-80{ }^{\circ} \mathrm{C}$ before analysis. The clinicopathological data of the patients were also collected. All research was performed in accordance with the guidelines of the 1975 Declaration of Helsinki and informed consent was obtained from all participants.

\subsection{NGS-Based Platform for Pre-S Genotyping}

The NGS-based quantitative detection of pre-S mutants in HBV-related HCC patients was carried out as described in our previous report [25]. Briefly, plasma DNA was prepared from each patient's plasma by using the DNeasy Blood Kit (Qiagen, Valencia, CA, USA) following the manufacturer's instructions. Next, the plasma DNA served as a template for two successive rounds of PCR amplification of the pre-S gene (comprising the pre-S1 and pre-S2 gene segments) with the high-fidelity Platinum SuperFi DNA polymerase (Invitrogen, Carlsbad, CA, USA) and specific primer pairs. The resulting pre-S gene PCR products were then directly subjected to NGS analysis by using the NextSeq 500 System supplemented with the bcl2fastq Conversion Software v2.20 (Illumina, San Diego, CA, USA) according to the manufacturer's instructions. Finally, the pre-S deletion types, regions, and percentages were acquired by using our customized scripts. To determine the cut-off percentage of the pre-S deletions, the pre-S gene PCR products were also analyzed by thymine/adenine (TA) cloning-based pre-S genotyping.

As shown in Figure 1, three types of pre-S deletions were detected: the pre-S1, pre-S2, and pre-S1 + pre-S2 deletions. The pre-S1 deletions were defined as deletions that took place solely in the pre-S1, but not in the pre-S2 gene segment; the pre-S2 deletions were defined as deletions that took place solely in the pre-S2 but not in the pre-S1 gene segment; the pre-S1 + pre-S2 deletions were defined as deletions that took place separately in both pre-S1 and pre-S2 gene segments or started in the pre-S1 and continuously expanded to the pre-S2 gene segment. Furthermore, the pre-S1 deletions and the pre-S1 + pre-S2 deletions were classified as deletions spanning the pre-S1 gene segment; the pre-S2 deletions and the pre-S1 + pre-S2 deletions were classified as deletions spanning the pre-S2 gene segment. 


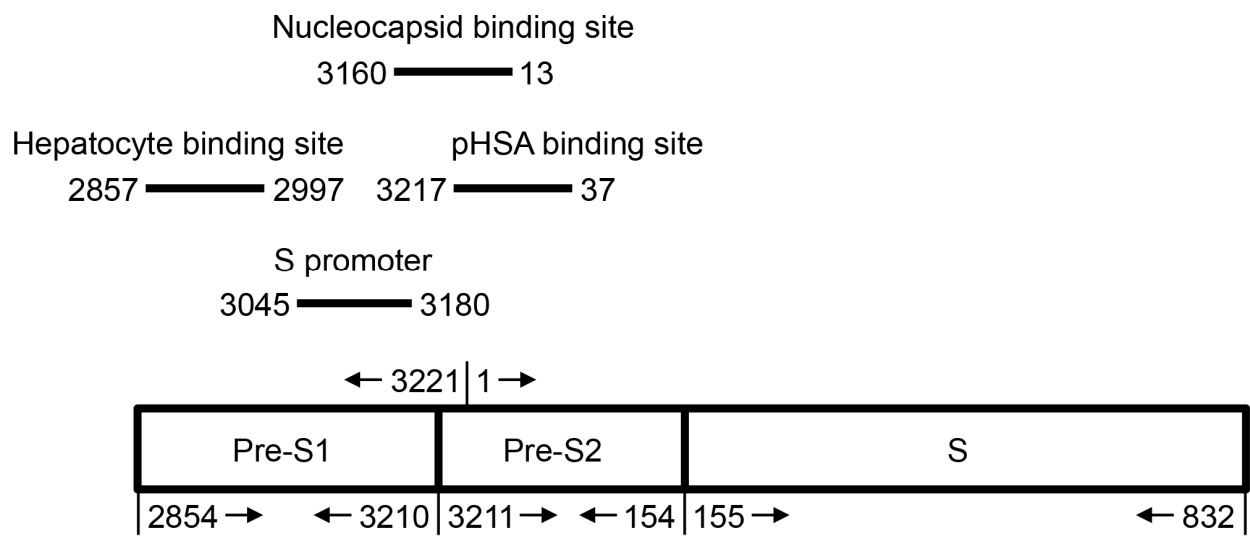

Patient No. 22

Pre-S1 deletions

ㄱ.

$28552872(18 \mathrm{nt})$

Pre-S2 deletions

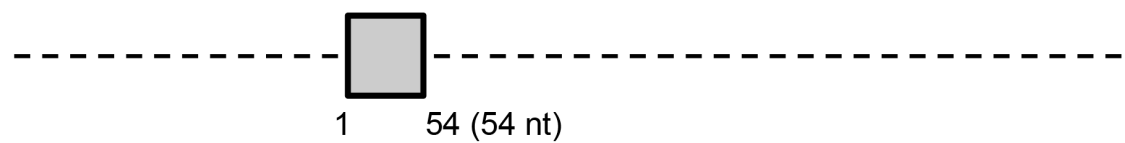

Pre-S1+pre-S2 deletions

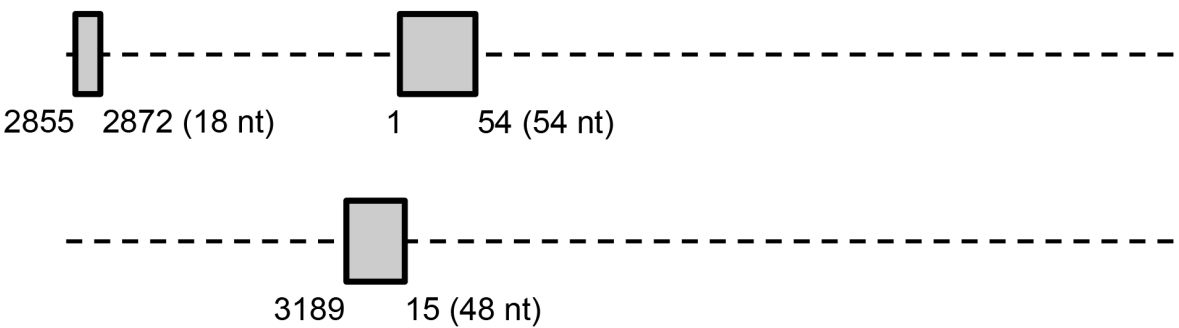

Figure 1. Schematic representation of HBV pre-S deletions. The HBV surface gene is composed of three gene segments: the pre-S1, pre-S2, and S gene segments. The numbers on the top and bottom of the diagram indicate the nucleotide (nt) positions of each gene segment in the circular HBV genome that starts at nt 1 and goes clockwise and ends at nt 3221. There are three types of pre-S deletions: the pre-S1, pre-S2, and pre-S1 + pre-S2 deletions. The pre-S1 deletions took place solely in the pre-S1 gene segment (nt 2854-3210); the pre-S2 deletions took place solely in the pre-S2 gene segment (nt 3211-3221, 1-154); the pre-S1 + pre-S2 deletions took place concurrently in both the pre-S1 and pre-S2 gene segments as two separate sites or as one site spanning those two gene segments. Shown are the representative deletion patterns from patient no. 22, who had all three types of pre-S deletions; the pre-S deletions with the highest frequency in each type were the pre-S1 deletion (nt 2855-2872), the pre-S2 deletion (nt 1-54), and the pre-S1 + pre-S2 deletion (nt 2855-2872, 1-54) (Table S1). Although the frequency was relatively lower, the pre-S1 + pre-S2 deletion (nt 3189-15) was shown to exemplify the deletions starting in the pre-S1 (nt 3189-3210) and continuously expanding to the pre-S2 (nt 3211-3221, 1-15) gene segment. The deletion size is shown in parentheses. Four representative functional sites encompassed within the pre-S gene are shown above the diagram. Abbreviations: pHSA, polymerized human serum albumin. 


\subsection{Statistical Analysis}

The univariate and multivariate analyses of prognostic factors for overall and recurrence-free survival were conducted by the Cox proportional-hazards regression model. The overall and recurrence-free survival curves were estimated by the Kaplan-Meier method and compared by the log-rank test. The receiver operating characteristic (ROC) curves of prognostic factors were established for discriminating patients with HCC recurrence from those without and the area under the ROC curves (AUCs) were calculated and compared with the Hanley-McNeil test. A $p$ value $<0.05$ was considered significant.

\section{Results}

\subsection{Clinicopathological Profiles of the HBV-Related HCC Patients}

The clinicopathological characteristics of the 75 HBV-related HCC patients enrolled in this study are summarized in Table 1. There were 68 (91\%) men and seven (9\%) women. The median age of all patients was 53 years (range, 26 to 78). Sixty (80\%) patients had genotype B and 15 (20\%) patients had genotype C HBV infection. HBV DNA was detected in $74(99 \%)$ patients at a median of $2.1 \times 10^{4}$ copies $/ \mathrm{mL}$ (range, 21.5 to $1.5 \times 10^{8}$ ). Among the 65 patients with available data, all were HBsAg positive. Among the 71 patients with available data, 62 (83\%) were HBV e antigen (HBeAg) negative. Tumor size was recorded for all patients with a median of $4.5 \mathrm{~cm}$ (range, 1.1 to 19.5). All patients received curative surgical resection. Among them, 52 (69\%) patients developed HCC recurrence and 16 (21\%) patients died of disease after surgery. As shown in Figure S1A,B, the OS and RFS for patients were 26.9 months (range, 6.8 to 161.1) and 11.2 months (range, 1.5 to 72.3 ), respectively.

Table 1. Clinicopathological characteristics of 75 HBV-related HCC patients enrolled in this study.

\begin{tabular}{|c|c|c|}
\hline Characteristics & No. of Patients & Median (Range) \\
\hline Age (years) & 75 & $53(26-78)$ \\
\hline$>50$ & 48 & $60(51-78)$ \\
\hline$\leq 50$ & 27 & $43(26-50)$ \\
\hline Gender (men/women) & $68 / 7$ & \\
\hline Smoking (yes/no) & $31 / 44$ & \\
\hline Alcohol (yes/no) & $29 / 46$ & \\
\hline HBsAg (positive/negative/NA) & $65 / 0 / 10$ & \\
\hline HBeAg (positive/negative/NA) & $9 / 62 / 4$ & \\
\hline HBV genotype $(\mathrm{B} / \mathrm{C})$ & $60 / 15$ & \\
\hline HBV DNA $(I U / m L)\left(20-1.7 \times 10^{8} /<20\right)^{a}$ & $74 / 1$ & $2.1 \times 10^{4}\left(21.5-1.5 \times 10^{8}\right)^{\mathrm{c}}$ \\
\hline$>1 \times 10^{4}$ & 42 & $4.3 \times 10^{5}\left(1.2 \times 10^{4}-1.5 \times 10^{8}\right)$ \\
\hline$\leq 1 \times 10^{4}$ & 32 & $8.4 \times 10^{2}\left(21.5-9.3 \times 10^{3}\right)$ \\
\hline Albumin (g/dL) & 75 & $3.7(1.2-4.9)$ \\
\hline$>3.8$ & 30 & $4.2(3.9-4.9)$ \\
\hline$\leq 3.8$ & 45 & $3.3(1.2-3.8)$ \\
\hline AST (U/L) & 75 & $60(14-1052)$ \\
\hline$>34$ & 61 & $79(35-1052)$ \\
\hline$\leq 34$ & 14 & $27(14-34)$ \\
\hline $\operatorname{ALT}(\mathrm{U} / \mathrm{L})$ & 75 & $55(13-1338)$ \\
\hline$>40$ & 50 & $96.5(41-1338)$ \\
\hline$\leq 40$ & 25 & $31(13-40)$ \\
\hline $\operatorname{AFP}(\mathrm{ng} / \mathrm{mL})(\leq 54,000 />54,000)^{\mathrm{b}}$ & $71 / 4$ & $26.7(1.8-36,600.0)^{d}$ \\
\hline$>400$ & 28 & $1920(461.7-36,600.0)$ \\
\hline$\leq 400$ & 47 & $13.8(1.8-271.0)$ \\
\hline Tumor size $(\mathrm{cm})$ & 75 & $4.5(1.1-19.5)$ \\
\hline$>5$ & 37 & $10.0(5.5-19.5)$ \\
\hline$\leq 5$ & 38 & $2.4(1.1-4.5)$ \\
\hline Tumor encapsulation (yes/no/NA) & $42 / 20 / 13$ & \\
\hline Lymph node involvement (yes/no) & $8 / 67$ & \\
\hline
\end{tabular}


Table 1. Cont.

\begin{tabular}{ccc}
\hline Characteristics & No. of Patients & Median (Range) \\
\hline Portal vein thrombosis (yes/no) & $5 / 70$ & \\
Vascular invasion (yes/no) & $27 / 48$ & \\
Distant metastasis (yes/no) & $8 / 67$ & \\
Steatosis grade (0/1/2/3/NA) & $14 / 10 / 1 / 0 / 50$ & \\
Metavir inflammation score (0/1/2/3/NA) & $4 / 35 / 5 / 0 / 31$ & \\
Ishak fibrosis score (0/1/2/3/4/5/6/NA) & $5 / 13 / 12 / 8 / 3 / 4 / 11 / 19$ & \\
Child-Pugh cirrhosis score (A/B/C) & $57 / 16 / 2$ & \\
CLIP score (0/1/2/3/4/5/6) & $33 / 23 / 10 / 8 / 1 / 0 / 0$ & $11.2(1.5-72.3)^{\mathrm{e}}$ \\
Tumor differentiation grade (1/2/3/4) & $2 / 36 / 36 / 1$ & $26.9(6.8-161.1)^{\mathrm{f}}$ \\
BCLC stage (A/B/C/D) & $38 / 29 / 7 / 1$ & \\
AJCC TNM stage (I/II/IIIA/IIIB/IIIC/IVA/IVB) & $40 / 20 / 7 / 5 / 3 / 0 / 0$ & $40 / 35$ \\
Antiviral therapy after surgery (yes/no) & $52 / 23$ & \\
HCC recurrence after surgery (month) (yes/no) & $16 / 59$ & \\
Survival after surgery (month) (dead/alive) &
\end{tabular}

${ }^{a}$ HBV DNA was measured with a detection range of 20 to $1.7 \times 10^{8} \mathrm{IU} / \mathrm{mL} .{ }^{\mathrm{b}}$ AFP was measured with the highest detection limit of 54,000 ng/mL. ${ }^{c, d}$ Only data within the detection range were analyzed. ${ }^{e}$ Shown was the time to recurrence after surgery. ${ }^{\mathrm{f}}$ Shown was survival time in patients who died after surgery. Abbreviations: HBV, hepatitis B virus; $\mathrm{HCC}$, hepatocellular carcinoma; $\mathrm{HBeAg}$, hepatitis B e antigen; NA, not available; AST, aspartate aminotransferase; ALT, alanine aminotransferase; AFP, alpha-fetoprotein; CLIP, Cancer of the Liver Italian Program; BCLC, Barcelona Clinic Liver Cancer; AJCC, American Joint Committee on Cancer; TNM, tumor-node-metastasis.

\subsection{Pre-S Genotyping and Patient Grouping by the NGS-Based Platform}

The NGS- and TA cloning-based pre-S genotyping analyses were performed to detect pre-S deletions in the plasma of the $75 \mathrm{HBV}$-related HCC patients. As shown in Table S1, the TA cloning result provided information on pre-S deletion types and regions. However, the NGS result provided information on not only the pre-S deletion types and regions, but also the percentage of each of three types of pre-S deletions including the pre-S1, pre-S2, and pre-S1 + pre-S2 deletions. By matching the result of NGS with that of TA cloning, the corresponding pre-S gene DNA detected by both analyses had the lowest percentage of $4.643 \%$, as shown by the pre-S1 deletion DNA in the patient no. 70 . Therefore, we set the percentage of $4.643 \%$ as the cut-off percentage value to determine the pre-S deletion types of each patient and divide the patients into distinct pre-S genotype groups. As shown in Table 2, up to 46 of $75(61 \%)$ patients had pre-S deletions. Among them, $15(20 \%)$ patients had only pre-S1 deletions, six ( $8 \%$ ) patients had only pre-S2 deletions, seven (9\%) patients had both pre-S1 and pre-S2 deletions, four (5\%) patients had both pre-S1 and pre-S1 + pre-S2 deletions, two (3\%) patients had both pre-S2 and pre-S1 + pre-S2 deletions, and $12(16 \%)$ patients had all three types of pre-S deletions. In addition, up to $40(53 \%)$ and $31(41 \%)$ of 75 patients had deletions spanning the pre-S1 and pre-S2 gene segments, respectively. Alternatively, the patients analyzed by NGS could also be classified into quarters in accordance with the percentage of any one or two or all three types of pre-S deletions from the lowest to the highest (designated I to IV, respectively).

Moreover, there was a tendency for the patients without pre-S deletions to have an extremely higher percentage of wild-type pre-S gene DNA in plasma than those with. As shown in Table S1, all 29 patients without pre-S deletions had $>90 \%$ of wild-type pre-S gene DNA, whereas only four of 46 patients with pre-S deletions had $>90 \%$ of wild-type pre-S gene DNA. Overall, the size of pre-S deletions with the highest frequency in each type ranged from one to 294 nucleotides in number (Table S1). The distribution of pre-S1 deletions prevalently covered the front half of the pre-S1 gene segment that partly overlapped with the hepatocyte binding site and S promoter region; the pre-S2 deletions were also predominantly distributed in the front half of the pre-S2 gene segment that was partly covered with the binding sites of nucleocapsid and polymerized human serum albumin (pHSA) (Tables 1 and S1). 
Table 2. Summary of NGS-based pre-S genotyping result in 75 HBV-related HCC patients.

\begin{tabular}{|c|c|}
\hline Pre-S Del Type of Patients ${ }^{a}$ & No. of Patients (\%) $b$ \\
\hline Total patients & $75(100)$ \\
\hline Patients without del spanning pre-S gene segments & $29(39)$ \\
\hline Patients with del spanning pre-S gene segments & $46(61)$ \\
\hline Patients with only pre-S1 del & $15(20)$ \\
\hline Patients with only pre-S2 del & $6(8)$ \\
\hline Patients with only pre-S1 + pre-S2 del & $0(0)$ \\
\hline Patients with both pre-S1 and pre-S2 del & $7(9)$ \\
\hline Patients with both pre-S1 and pre-S1 + pre-S2 del & $4(5)$ \\
\hline Patients with both pre-S2 and pre-S1 + pre-S2 del & $2(3)$ \\
\hline Patients with all three types of pre-S del & $12(16)$ \\
\hline Patients with del spanning the pre-S1 gene segment & $40(53)$ \\
\hline Patients with del spanning the pre-S2 gene segment & $31(41)$ \\
\hline Pre-S Del Percentage of Patients & No. of Patients (\%) \\
\hline Pre-S1 del percentage ${ }^{c}$ & $75(100)$ \\
\hline $\mathrm{I}(\leq 1.895)^{\mathrm{d}}$ & $19(25)$ \\
\hline II $(>1.895)$ & $19(25)$ \\
\hline III $(>5.629)$ & $18(24)$ \\
\hline $\operatorname{IV}(>28.270)$ & $19(25)$ \\
\hline Pre-S2 del percentage & $75(100)$ \\
\hline $\mathrm{I}(\leq 0.643)$ & $19(25)$ \\
\hline II $(>0.643)$ & $19(25)$ \\
\hline III $(>1.824)$ & $18(24)$ \\
\hline IV $(>13.666)$ & $19(25)$ \\
\hline Pre-S1 + pre-S2 del percentage & $75(100)$ \\
\hline $\mathrm{I}(\leq 0.015)$ & $19(25)$ \\
\hline II $(>0.015)$ & $18(24)$ \\
\hline III $(>0.442)$ & $19(25)$ \\
\hline $\operatorname{IV}(>2.975)$ & $19(25)$ \\
\hline Pre-S1 plus pre-S2 del percentage & $75(100)$ \\
\hline $\mathrm{I}(\leq 2.725)$ & $18(24)$ \\
\hline $\mathrm{II}(>2.725)$ & $19(25)$ \\
\hline III $(>18.539)$ & $19(25)$ \\
\hline IV $(>49.938)$ & $19(25)$ \\
\hline Pre-S1 plus pre-S1 + pre-S2 del percentage & 75 (100) \\
\hline $\mathrm{I}(\leq 2.043)$ & $18(24)$ \\
\hline II $(>2.043)$ & $19(25)$ \\
\hline III $(>6.332)$ & $20(27)$ \\
\hline IV $(>44.201)$ & $18(24)$ \\
\hline Pre-S2 plus pre-S1 + pre-S2 del percentage & $75(100)$ \\
\hline $\mathrm{I}(\leq 0.689)$ & $18(24)$ \\
\hline II $(>0.689)$ & $20(27)$ \\
\hline III $(>2.109)$ & $19(25)$ \\
\hline IV $(>24.995)$ & $18(24)$ \\
\hline All three types of pre-S del percentage & $75(100)$ \\
\hline $\mathrm{I}(\leq 2.828)$ & $18(24)$ \\
\hline $\mathrm{II}(>2.828)$ & $20(27)$ \\
\hline $\mathrm{III}(>21.666)$ & $18(24)$ \\
\hline IV $(>58.035)$ & $19(25)$ \\
\hline
\end{tabular}

a Pre-S del type of patients was determined by a cut-off percentage of $4.643 .{ }^{b}$ Percentage of patients was rounded off to the nearest integer. ${ }^{c}$ Patients were divided into quarters of the distribution of indicated type of pre-S del percentage from the lowest to the highest (designated I to IV, respectively). ${ }^{\mathrm{d}}$ Threshold percentage of indicated pre-S del type for each quarter was shown in parenthesis. Abbreviations: del, deletion.

3.3. Patients with Either Deletions Spanning the Pre-S2 Gene Segment or High Percentage of Pre-S2 Plus Pre-S1 + Pre-S2 Deletions as a High-Risk Population for HCC Recurrence after Surgical Resection

The correlations of pre-S deletion types and clinicopathological factors with OS and RFS in the 75 HBV-related HCC patients after surgical resection were examined. As shown in Tables Table 3 and S2, among the clinicopathological factors analyzed, only the Child-Pugh cirrhosis score and the AJCC TNM stage were significantly and independently associated with OS (Child-Pugh cirrhosis score, hazard ratio $(\mathrm{HR})=2.974,95 \%$ confidence interval $(\mathrm{CI}) 1.035$ to $8.549, p$ value $=0.0430$; AJCC 
TNM stage, $\mathrm{HR}=3.146,95 \%$ CI 1.041 to 9.510, $p$ value $=0.0423$ ) and RFS (Child-Pugh cirrhosis score, $\mathrm{HR}=2.182,95 \%$ CI 1.142 to 4.171, $p$ value $=0.0182$; AJCC TNM stage, $\mathrm{HR}=3.667,95 \%$ CI 1.853 to 7.258 , $p$ value $=0.0002)$ in patients. As shown in Figure $2 \mathrm{~A}, \mathrm{~B}$ and Figure S2A,B, patients with Child-Pugh cirrhosis score (B/C) and AJCC TNM stage (IIIA/IIIB/IIIC/IVA/IVB) had a significantly shorter median OS (Child-Pugh cirrhosis score, 12.7 vs. 35.0 months, $p$ value $=0.0324$; AJCC TNM stage, 16.6 vs. 32.9 months, $p$ value $=0.0306$ ) and RFS (Child-Pugh cirrhosis score, 5.1 vs. 15.1 months, $p$ value $=0.0093$; AJCC TNM stage, 5.0 vs. 17.9 months, $p$ value $<0.0001)$ than those with Child-Pugh cirrhosis score (A) and AJCC TNM stage (I/II), respectively. No significant correlations were observed between pre-S deletion types and OS in patients (Figure S2C and Table S2). However, the deletions spanning the pre-S2 gene segment, rather than the other pre-S deletion types, were defined as an independent prognostic factor for RFS in patients (HR $=2.114,95 \%$ CI 1.203 to 3.714, $p$ value $=0.0092)$ (Table 3). Patients with deletions spanning the pre-S2 gene segment had a significantly shorter median RFS (8.5 vs. 32.9 months, $p$ value $=0.0283$ ) than those without (Figure $2 \mathrm{C}$ ).

Table 3. Univariate and multivariate analyses of pre-S deletion type for recurrence-free survival in 75 HBV-related HCC patients.

\begin{tabular}{|c|c|c|c|c|c|c|}
\hline \multirow{2}{*}{ Characteristics } & \multicolumn{3}{|c|}{ Univariate Analysis } & \multicolumn{3}{|c|}{ Multivariate Analysis } \\
\hline & HR & $95 \%$ CI & $p$ Value & HR & $95 \%$ CI & $p$ Value \\
\hline Age (years) (>50 vs. $\leq 50)$ & 0.951 & $0.532-1.700$ & 0.8666 & & & \\
\hline Gender (men vs. women) & 1.043 & $0.414-2.627$ & 0.9284 & & & \\
\hline Smoking (yes vs. no) & 0.886 & $0.503-1.560$ & 0.6750 & & & \\
\hline Alcohol (yes vs. no) & 0.884 & $0.494-1.580$ & 0.6773 & & & \\
\hline \multicolumn{7}{|l|}{ HBsAg (positive vs. negative) ${ }^{a}$} \\
\hline HBeAg (positive vs. negative) $b$ & 1.234 & $0.523-2.910$ & 0.6307 & & & \\
\hline HBV genotype (B vs. C) & 0.583 & $0.304-1.117$ & 0.1040 & & & \\
\hline $\operatorname{HBV}$ DNA $(\mathrm{IU} / \mathrm{mL})\left(>1 \times 10^{4} \text { vs. } \leq 1 \times 10^{4}\right)^{\mathrm{c}}$ & 1.645 & $0.934-2.895$ & 0.0846 & & & \\
\hline Albumin $(\mathrm{g} / \mathrm{dL})(>3.8$ vs. $\leq 3.8)$ & 0.551 & $0.288-1.092$ & 0.0585 & & & \\
\hline AST (U/L) (>34 vs. $\leq 34)$ & 0.865 & $0.444-1.684$ & 0.6691 & & & \\
\hline $\operatorname{ALT}(\mathrm{U} / \mathrm{L})(>40$ vs. $\leq 40)$ & 0.797 & $0.456-1.394$ & 0.4267 & & & \\
\hline $\operatorname{AFP}(\mathrm{ng} / \mathrm{mL})(>400$ vs. $\leq 400)$ & 1.305 & $0.745-2.285$ & 0.3524 & & & \\
\hline Tumor size $(\mathrm{cm})(>5$ vs. $\leq 5)$ & 1.490 & $0.863-2.572$ & 0.1525 & & & \\
\hline Tumor encapsulation (yes vs. no) ${ }^{d}$ & 0.901 & $0.474-1.713$ & 0.7508 & & & \\
\hline Lymph node involvement (yes vs. no) & 0.333 & $0.104-1.071$ & 0.0652 & & & \\
\hline Portal vein thrombosis (yes vs. no) & 1.668 & $0.600-4.633$ & 0.3264 & & & \\
\hline Vascular invasion (yes vs. no) & 1.677 & $0.962-2.924$ & 0.0681 & & & \\
\hline Distant metastasis (yes vs. no) & 2.259 & $0.999-5.101$ & 0.0502 & & & \\
\hline Steatosis grade $(2 / 3$ vs. $0 / 1) \mathrm{e}^{\mathrm{e}}$ & 3.473 & $0.418-28.879$ & 0.2493 & & & \\
\hline Metavir inflammation score $(2 / 3 \text { vs. } 0 / 1)^{f}$ & 0.731 & $0.256-2.088$ & 0.5583 & & & \\
\hline Ishak fibrosis score $(4 / 5 / 6 \text { vs. } 0 / 1 / 2 / 3)^{g}$ & 1.261 & $0.670-2.373$ & 0.4714 & & & \\
\hline Child-Pugh cirrhosis score (B/C vs. A) & 2.189 & $1.195-4.013$ & $0.0112 *$ & 2.182 & $1.142-4.171$ & $0.0182 *$ \\
\hline CLIP score (4/5/6 vs. $0 / 1 / 2 / 3)$ & 2.426 & $0.328-17.911$ & 0.3850 & & & \\
\hline Tumor differentiation (3/4 vs. $1 / 2)$ & 1.246 & $0.722-2.150$ & 0.4288 & & & \\
\hline BCLC stage (C/D vs. A/B) & 1.927 & $0.867-4.284$ & 0.1077 & & & \\
\hline AJCC TNM stage (IIIA/IIIB/IIIC/IVA/IVB vs. I/II) & 4.048 & $2.123-7.719$ & $<0.0001^{* * *}$ & 3.667 & $1.853-7.258$ & $0.0002 * * *$ \\
\hline Antiviral therapy after surgery (yes vs. no) & 1.176 & $0.674-2.051$ & 0.5684 & & & \\
\hline Del spanning pre-S gene segments (yes vs. no) & 1.315 & $0.742-2.332$ & 0.3477 & & & \\
\hline Only pre-S1 del (yes vs. no) & 0.590 & $0.277-1.257$ & 0.1715 & & & \\
\hline Only pre-S2 del (yes vs. no) & 1.421 & $0.564-3.580$ & 0.4557 & & & \\
\hline \multicolumn{7}{|l|}{ Only pre-S1 + pre-S2 del (yes vs. no) ${ }^{\mathrm{h}}$} \\
\hline Both pre-S1 and pre-S2 del (yes vs. no) & 1.260 & $0.453-3.505$ & 0.6573 & & & \\
\hline Both pre-S1 and pre-S1 + pre-S2 del (yes vs. no) & 2.460 & $0.876-6.909$ & 0.0876 & & & \\
\hline Both pre-S2 and pre-S1 + pre-S2 del (yes vs. no) & 1.621 & $0.393-6.690$ & 0.5042 & & & \\
\hline All three types of pre-S del (yes vs. no) & 1.352 & $0.694-2.632$ & 0.3755 & & & \\
\hline Del spanning the pre-S1 gene segment (yes vs. no) & 1.165 & $0.673-2.015$ & 0.5859 & & & \\
\hline Del spanning the pre-S2 gene segment (yes vs. no) & 1.825 & $1.058-3.149$ & $0.0307^{*}$ & 2.114 & $1.203-3.714$ & $0.0092 * *$ \\
\hline
\end{tabular}

a There were no patients negative for HBsAg for analysis. ${ }^{\mathrm{b}}$ Only 71 patients with available data were analyzed.

${ }^{c}$ Only 74 patients with available data were analyzed. ${ }^{d}$ Only 62 patients with available data were analyzed. ${ }^{e}$ Only 25 patients with available data were analyzed. ${ }^{\mathrm{f}}$ Only 44 patients with available data were analyzed. $\mathrm{g}$ Only 56 patients with available data were analyzed. ${ }^{\mathrm{h}}$ There were no patients with only pre-S1 + pre-S2 del for analysis. ${ }^{*} p$ value $<0.05$; ${ }^{* *} p$ value $<0.01$; ${ }^{* * *} p$ value $<0.001$. Abbreviations: HR, hazard ratio; CI, confidence interval; del, deletion; vs., versus. 
A

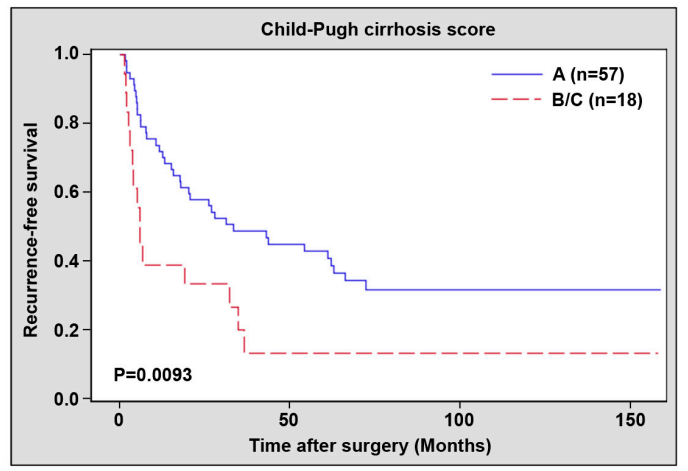

\section{C}

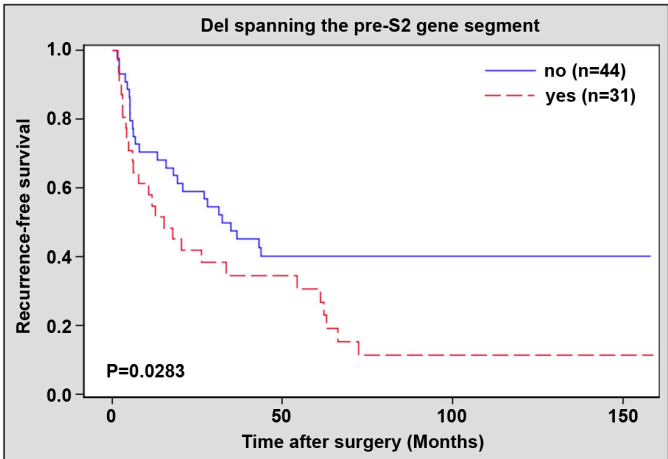

$\mathbf{E}$

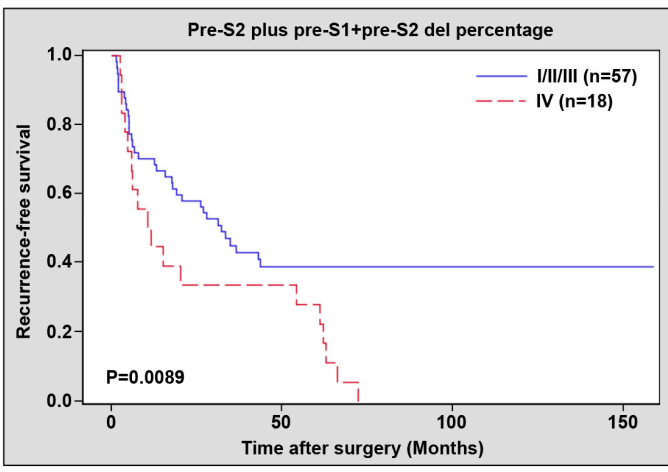

B

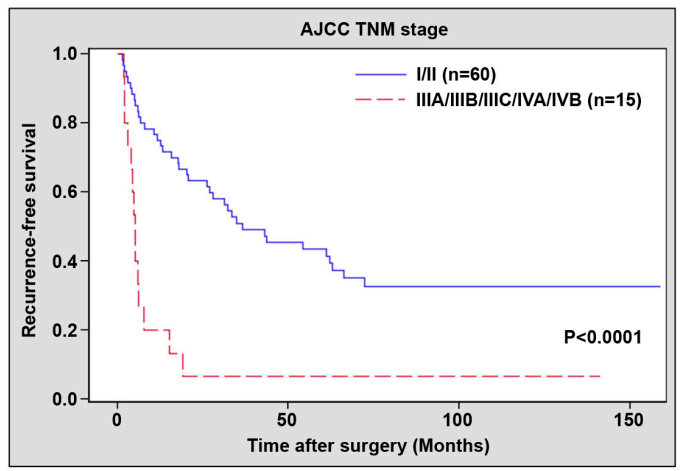

D

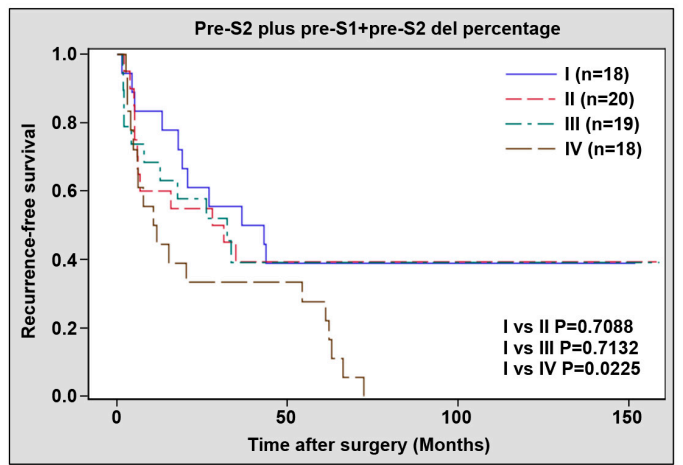

$\mathbf{F}$

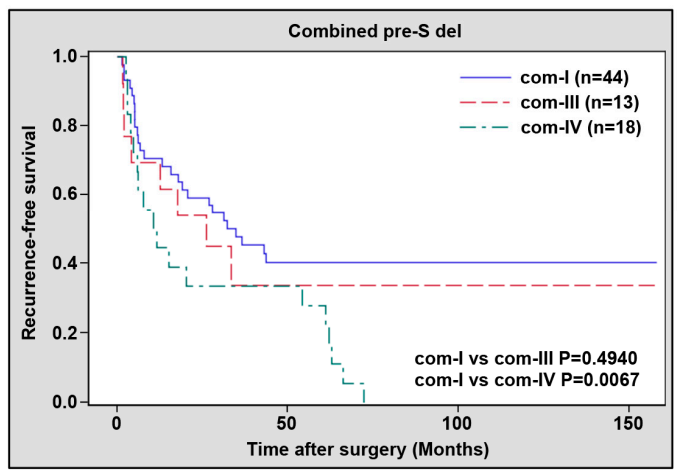

Figure 2. Kaplan-Meier curves of RFS differences in the $75 \mathrm{HBV}$-related HCC patients after surgical resection. (A) RFS in patients with Child-Pugh cirrhosis score A versus B/C. (B) RFS in patients with AJCC TNM stage I/II versus IIIA/IIIB/IIIC/IVA/IVB. (C) RFS in patients with (yes) versus without (no) deletions spanning the pre-S2 gene segment. (D) RFS in patients with pre-S2 plus pre-S1 + pre-S2 deletions percentage I versus II, III, or IV, respectively. (E) RFS in patients with pre-S2 plus pre-S1 + pre-S2 deletions percentage I/II/III versus IV. (F) RFS in patients with combined pre-S deletions com-I versus com-III or com-IV, respectively. RFS rate was plotted against months after surgery. $p$ values and numbers ( $\mathrm{n}$ ) of patients were indicated in the plots. A $p$ value $<0.05$ was considered significant.

Furthermore, the associations of the percentage of pre-S deletion types with OS and RFS in the 75 HBV-related HCC patients after surgical resection were investigated. As shown in Figure S2D and Table S3, there were no significant correlations between the percentage of pre-S deletion types and OS in patients. However, the highest percentage of pre-S2 plus pre-S1 + pre-S2 deletion group (IV, percentage $>24.995)$ showed a significantly negative prognostic impact on RFS (HR $=2.351,95 \% \mathrm{CI}$ 1.073 to $5.153, p$ value $=0.0328)$ compared with the lowest percentage of pre-S2 plus pre-S1 + pre-S2 deletion group $(\mathrm{I}$, percentage $\leq 0.689$ ) in patients (Table 4$)$. As shown in Figure 2D, patients in group 
IV had significantly poorer RFS (median RFS, 11.2 vs. 19.0 months, $p$ value $=0.0225$ ) than those in the group I. At 72.3 months after surgery, all patients in group IV developed HCC recurrence, whereas seven of $18(39 \%)$ patients in group I still did not suffer HCC recurrence. Consistently, when patients were divided into two groups, the high percentage (IV, percentage $>24.995)$ and low percentage (I/I/III, percentage $\leq 24.995)$ of pre-S2 plus pre-S1 + pre-S2 deletions, the high percentage group was significantly associated with poor RFS compared with the low percentage group of patients $(\mathrm{HR}=2.102$, $95 \%$ CI 1.148 to 3.850, $p$ value $=0.0161)($ Table 4$)$. As shown in Figure 2E, when all patients in the high percentage group developed HCC recurrence after surgery, 23 of $57(40 \%)$ patients in the low percentage group remaining did not suffer HCC recurrence.

Table 4. Univariate and multivariate analyses of pre-S deletion percentage for recurrence-free survival in 75 HBV-related HCC patients.

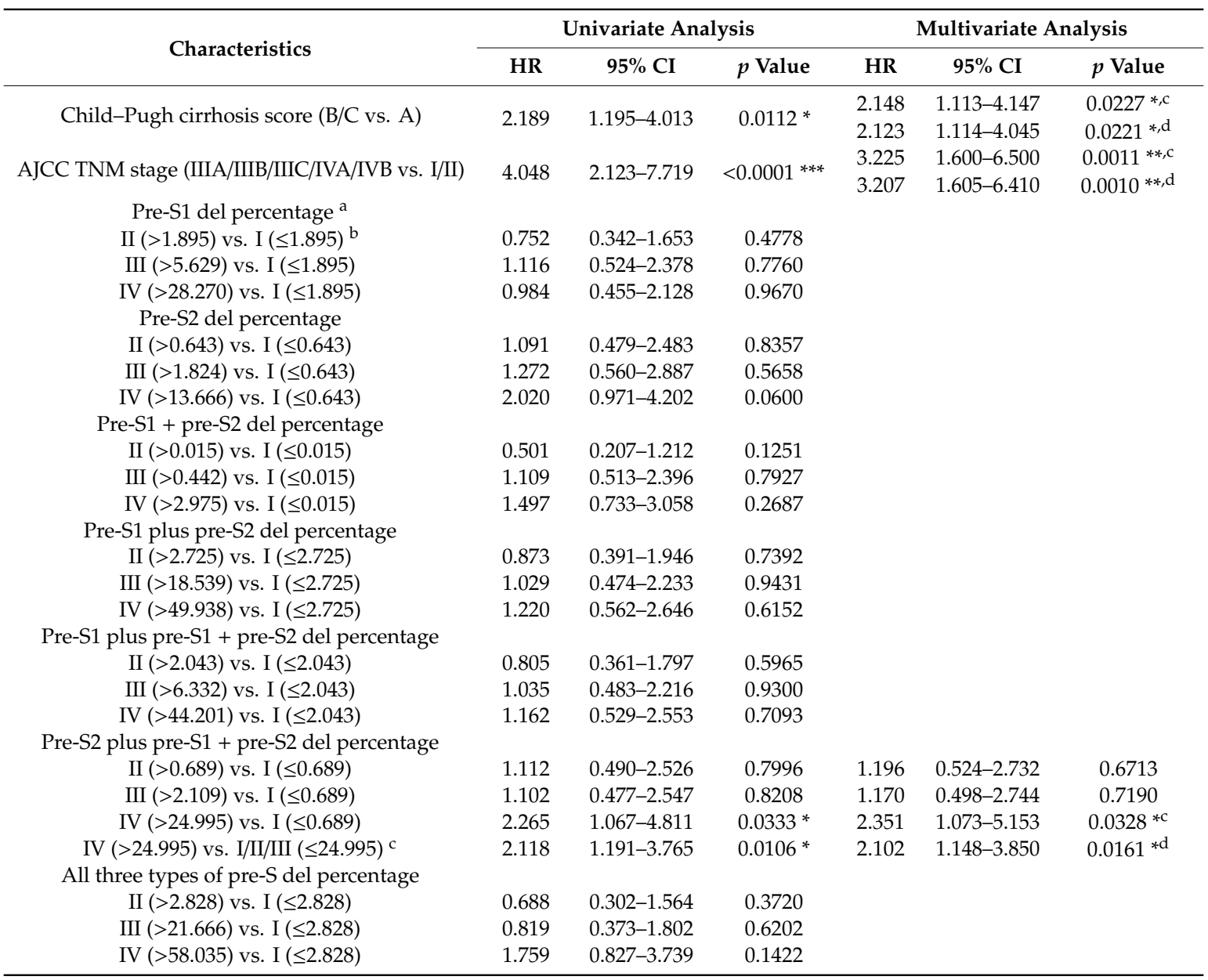

a Patients were divided into quarters of the distribution of indicated type of pre-S del percentage from the lowest to the highest (designated I to IV, respectively). ${ }^{b}$ Threshold percentage of indicated pre-S del type for each quarter was shown in parenthesis. ${ }^{c, d}$ Multivariate analysis was performed between these characteristics accordingly. ${ }^{*} p$ value $<0.05 ;{ }^{* *} p$ value $<0.01 ;{ }^{* *} p$ value $<0.001$. Abbreviations: HR, hazard ratio; CI, confidence interval; del, deletion.

3.4. Combination of Deletions Spanning the Pre-S2 Gene Segment and the Percentage of Pre-S2 Plus Pre-S1 + Pre-S2 Deletions as an Independent Prognostic Factor for HCC Recurrence after Surgical Resection

Next, the prognostic significance of the presence of deletions spanning the pre-S2 gene segment in combination with the high percentage of pre-S2 plus pre-S1 + pre-S2 deletions in the 75 HBV-related HCC patients after surgical resection was evaluated. Patients were divided into four groups based on the pre-S deletion types and percentages: com-I (44 patients), absence of deletions spanning the pre-S2 gene segment \& low percentage of pre-S2 plus pre-S1 + pre-S2 deletions (I/II/III, percentage $\leq 24.995)$; 
com-II (no patients), absence of deletions spanning the pre-S2 gene segment \& high percentage of pre-S2 plus pre-S1 + pre-S2 deletions (IV, percentage > 24.995); com-III (13 patients), presence of deletions spanning the pre-S2 gene segment \& low percentage of pre-S2 plus pre-S1 + pre-S2 deletions; and com-IV (18 patients), presence of deletions spanning the pre-S2 gene segment \& high percentage of pre-S2 plus pre-S1 + pre-S2 deletions. Because there were no patients falling into the group com-II, the prognostic significance was analyzed in the other groups compared with the group com-I. As shown in Figure S2E and Table S4, no significant differences in OS were found between the patient groups com-I and com-III as well as the groups com-I and com-IV. However, the presence of deletions spanning the pre-S2 gene segment in combination with the high percentage of pre-S2 plus pre-S1 + pre-S2 deletions (com-IV) was significantly and independently associated with poorer RFS (HR $=2.336,95 \% \mathrm{CI}$ 1.238 to $4.408, p$ value $=0.0088$ ) compared with the group com-I (Table 5). As shown in Figure $2 \mathrm{~F}$, when all patients in the group com-IV developed HCC recurrence after surgery, 18 of 44 (41\%) patients in the group com-I still did not suffer HCC recurrence. Although the median RFS for the patient group com-I versus com-IV was comparable (10.6 vs. 11.2 months), the differences in RFS between these two groups were statistically significant $(p$ value $=0.0067)$.

Table 5. Univariate and multivariate analyses of combined pre-S deletion for recurrence-free survival in 75 HBV-related HCC patients.

\begin{tabular}{|c|c|c|c|c|c|c|}
\hline \multirow{2}{*}{ Characteristics } & \multicolumn{3}{|c|}{ Univariate Analysis } & \multicolumn{3}{|c|}{ Multivariate Analysis } \\
\hline & HR & $95 \%$ CI & $p$ Value & HR & $95 \% \mathrm{CI}$ & $p$ Value \\
\hline Child-Pugh cirrhosis score (B/C vs. A) & 2.189 & $1.195-4.013$ & $0.0112 *$ & 2.213 & $1.154-4.244$ & $0.0168 *$ \\
\hline $\begin{array}{c}\text { AJCC TNM stage } \\
\text { (IIIA/IIIB/IIIC/IVA/IVB vs. I/II) }\end{array}$ & 4.048 & $2.123-7.719$ & $<0.0001^{* * *}$ & 3.440 & $1.689-7.005$ & $0.0007^{* * *}$ \\
\hline $\begin{array}{l}\text { Combined pre-S del }{ }^{a} \\
\text { com-II }^{b} \text { vs. com-I }\end{array}$ & & & & & & \\
\hline com-III vs. com-I & 1.294 & $0.585-2.863$ & 0.5242 & 1.764 & $0.780-3.986$ & 0.1726 \\
\hline com-IV vs. com-I & 2.237 & $1.222-4.097$ & $0.0091 * *$ & 2.336 & $1.238-4.408$ & $0.0088^{* *}$ \\
\hline
\end{tabular}

${ }^{a}$ Patients were divided into four groups based on pre-S del types and percentages: com-I, del spanning the pre-S2 gene segment (no) and pre-S2 plus pre-S1 + pre-S2 del percentage (I/II/III); com-II, del spanning the pre-S2 gene segment (no) \& pre-S2 plus pre-S1 + pre-S2 del percentage (IV); com-III, del spanning the pre-S2 gene segment (yes) \& pre-S2 plus pre-S1 + pre-S2 del percentage (I/I//III); and com-IV, del spanning the pre-S2 gene segment (yes) \& pre-S2 plus pre-S1 + pre-S2 del percentage (IV). ${ }^{b}$ There were no patients falling into the com-II group for analysis. ${ }^{*} p$ value $<0.05 ;{ }^{* *} p$ value $<0.01 ;{ }^{* * *} p$ value $<0.001$. Abbreviations: HR, hazard ratio; CI, confidence interval; del, deletion; com, combined.

So far, five independent prognostic factors for HCC recurrence after surgical resection were identified in the $75 \mathrm{HBV}$-related HCC patients, including the Child-Pugh cirrhosis score, the AJCC TNM stage, as well as deletions spanning the pre-S2 gene segment, the pre-S2 plus pre-S1 + pre-S2 deletions percentage, and both combined (combined pre-S deletion). The prognostic performance of these five factors was further compared. As shown in Figure 3, the pre-S2 plus pre-S1 + pre-S2 deletion percentage had the highest AUC $(0.6827,95 \%$ CI 0.5679 to 0.7975$)$ followed by the combined pre-S deletion $(0.6789,95 \%$ CI 0.5815 to 0.7764$)$ and then deletions spanning the pre-S2 gene segment $(0.6413$, 95\% CI 0.5311 to 0.7515$)$. The AUCs for the AJCC TNM stage $(0.6129,95 \%$ CI 0.5386 to 0.6872$)$ and the Child-Pugh cirrhosis score $(0.5790,95 \%$ CI 0.4851 to 0.6729$)$ were the lowest. 


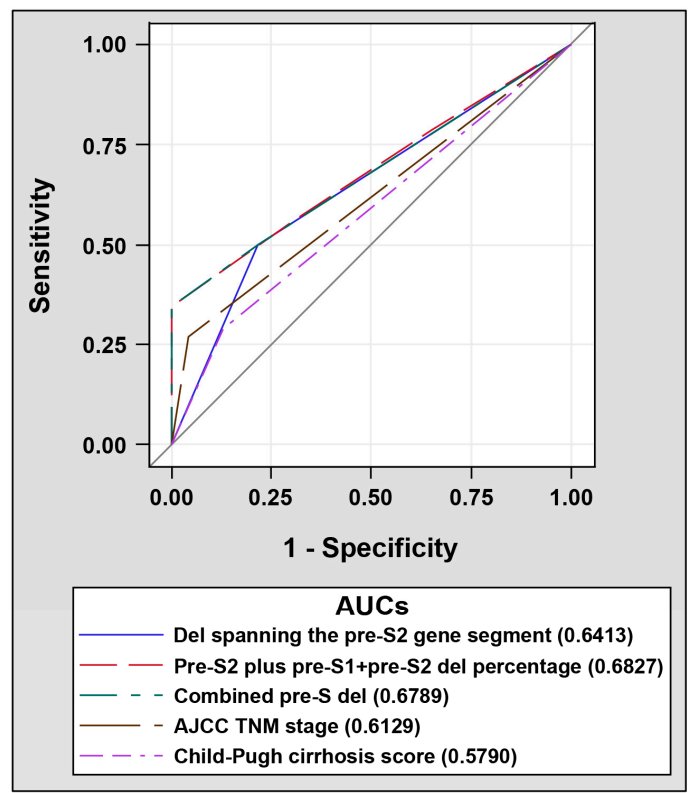

Figure 3. ROC curves of the selected prognostic factors in discriminating patients with HCC recurrence after surgical resection from those without. 52 patients with and 23 patients without HCC recurrence were analyzed. AUCs for selected prognostic factors, including deletions spanning the pre-S2 gene segment (solid blue line), the pre-S2 plus pre-S1 + pre-S2 deletions percentage (dashed red line), the combined pre-S deletions (dashed green line), the AJCC TNM stage (dashed brown line), and the Child-Pugh cirrhosis score (dashed purple line) were indicated in the plots.

\section{Discussion}

Although surgical resection is regarded as a potentially curable treatment for HCC patients, recurrence of HCC after surgery remains a frequent event, leading to poor patient survival $[4,8,9]$. The presence of HBV pre-S mutants has been well demonstrated as a valuable prognostic marker for HCC recurrence in patients after surgical resection [22-24]. Especially, the persistence of type II GGHs, which express pre-S2 mutants, in liver tissues or the relative level of pre-S2 mutants in serum samples represents an independent risk marker for the recurrence of HBV-related HCC in patients after surgical resection, even following antiviral treatment [22-24]. Therefore, development of an approach that can detect pre-S mutants with high sensitivity and accuracy may hold great promise in allowing for early diagnosis and treatment of recurrent HBV-related HCC, providing survival benefits for patients undergoing surgical resection.

Compared with current approaches that can provide only qualitative and semi-quantitative detection results of pre-S deletions [18,19,22], the NGS-based platform developed by our group can detect pre-S deletions quantitatively, accompanied with higher sensitivity and fidelity $[25,26]$. As a result, by means of this platform, the percentage of each of the three types of pre-S deletions including the pre-S1, pre-S2, and pre-S1 + pre-S2 deletions in plasma samples of HBV-related HCC patients could be well determined and patients could then be classified into distinctly defined groups according to not only the types, but also the percentages of pre-S deletions detected (Figure 4). First, on the basis of the types or percentages of pre-S deletions, we identified that either the presence of deletions spanning the pre-S2 gene segment (cut-off percentage of 4.643) or the high percentage of pre-S2 plus pre-S1 + pre-S2 deletions (percentage $>24.995$ ) was an independent prognostic factor for HCC recurrence after surgical resection. Next, we validated that the combination of these two pre-S deletion factors (both the types and percentages) was also an independent factor associated with HCC recurrence after surgery. Furthermore, we demonstrated that the presence of deletions spanning the pre-S2 gene segment and the high percentage of pre-S2 plus pre-S1 + pre-S2 deletions, either alone or in combination, had superior prognostic efficiency to other independent factors (the Child-Pugh cirrhosis score and the AJCC TNM 
stage) in predicting HCC recurrence in patients after surgical resection. Therefore, we suggest that upon analysis by the established NGS-based platform, patients with either or both deletions spanning the pre-S2 gene segment and the high percentage of pre-S2 plus pre-S1 + pre-S2 deletions are regarded as a high-risk population for HCC recurrence after surgical resection. Our NGS-based detection results consistently emphasize the significant association of pre-S2 mutants with HBV-related HCC recurrence after surgical resection.

A variety of prognostic markers have been proposed for HCC recurrence after surgical resection. Most of them are host oncoproteins and tumor suppressors in liver tissues [27]. For example, high level of oncoproteins c-Myc and $\beta$-catenin expression is associated with shorter RFS in HCC patients [28,29]. In addition, the combination of low level of tumor suppressor phosphatase and tensin homology and high level of oncoproteins proliferating cell nuclear antigen and p53 expression is correlated with poorer RFS in HCC patients [30]. Although these markers display significant prognostic values for HCC prognosis, their clinical utilization is severely hindered by the need and risk of invasive tissue biopsy-based detection procedures. In this study, we evaluated pre-S mutants (both the deletion types and percentages) as a plasma biomarker for predicting HCC recurrence after surgical resection. Compared with tissues, plasma is a more readily accessible specimen source and is commonly used as the so-called noninvasive liquid biopsy. Therefore, the NGS-based detection of pre-S mutants in plasma may hold a greater promise in clinical application, especially for patients unsuitable for needle biopsy of the liver. In addition, a high level of preoperative serum HBV DNA has been reported to be associated with postoperative HCC recurrence though the cut-off value for serum HBV DNA level and the postoperative follow-up time varies between different studies [31-33]. Furthermore, antiviral therapy, which suppresses HBV replication, thus decreasing serum HBV DNA level, has been shown to significantly improve RFS in HCC patients after surgical resection [34,35]. However, the beneficial effect of antiviral therapy is exclusively found in patients with a high level of preoperative serum HBV DNA and depends on continuous antiviral treatments after surgery [36]. In this study, neither the serum HBV DNA level nor antiviral therapy was observed to be associated with RFS in HCC patients; the former might be possibly because a different cut-off value was needed to divide patients, and the latter because not all patients enrolled in this study had high serum HBV DNA level and received antiviral therapy after surgery. Instead, the pre-S deletions detected by the NGS-based platform were evaluated as an independent prognostic factor for HCC recurrence. Consistent with our results, the type II GGHs harboring pre-S2 mutants in liver tissues have been shown to resist antiviral therapy, regardless of the decreased levels of serum HBV DNA, and is significantly implicated in the recurrence of HCC in patients after surgical resection [23]. Our results thus suggest that in some patient cohorts, pre-S mutants may have potentially better prognostic performance for HCC recurrence than other viral factors.

In the HBV replication cycle, the relaxed circular form of HBV DNA after entering the host hepatocytes will be converted into the covalently closed circular DNA that serves as the template for the production of HBV pregenomic RNA and gene products, followed by the assembly and release of HBV virions [37-39]. However, during the replication cycle, integration of HBV DNA into the host hepatocyte genome is a frequent event, potentially leading to insertional mutagenesis, genomic instability, and persistent viral gene expression that may promote hepatocyte transformation and eventually the development of HCC [40-42]. HBV DNA integrations occur in the early stage of chronic $\mathrm{HBV}$ infection and can be detected in about $30 \%$ of adjacent non-tumor cells and up to $90 \%$ of $\mathrm{HCC}$ cells $[43,44]$. Therefore, the HBV DNA fragments obtained from blood samples of HBV-related HCC patients may be derived from two sources, one associated with HBV virions and the other released from dead hepatocytes or HCC cells that harbor HBV DNA integrations. A study by Jia et al. compared the deletion patterns and incidences of pre-S gene in matched serum, adjacent non-tumor tissues, and tumor tissues from $40 \mathrm{HBV}$-related HCC patients, and showed that deletions in the pre-S gene among the different samples exhibited consistent distribution and similar abundance [45]. This finding supports that pre-S mutants may originate from the integrated HBV DNA that contains pre-S deletions in HBV-infected hepatocytes and HCC cells, possibly explaining the association of pre-S mutants with 
HCC recurrence in patients after surgical resection, even after receiving postoperative antiviral therapy. Further investigations are still needed to compare the profiles of pre-S deletions in matched blood and liver tissue specimens obtained from HBV-related HCC patients before and after surgical resection in a long-term follow-up and evaluate their clinical and pathological implications in HCC recurrence.

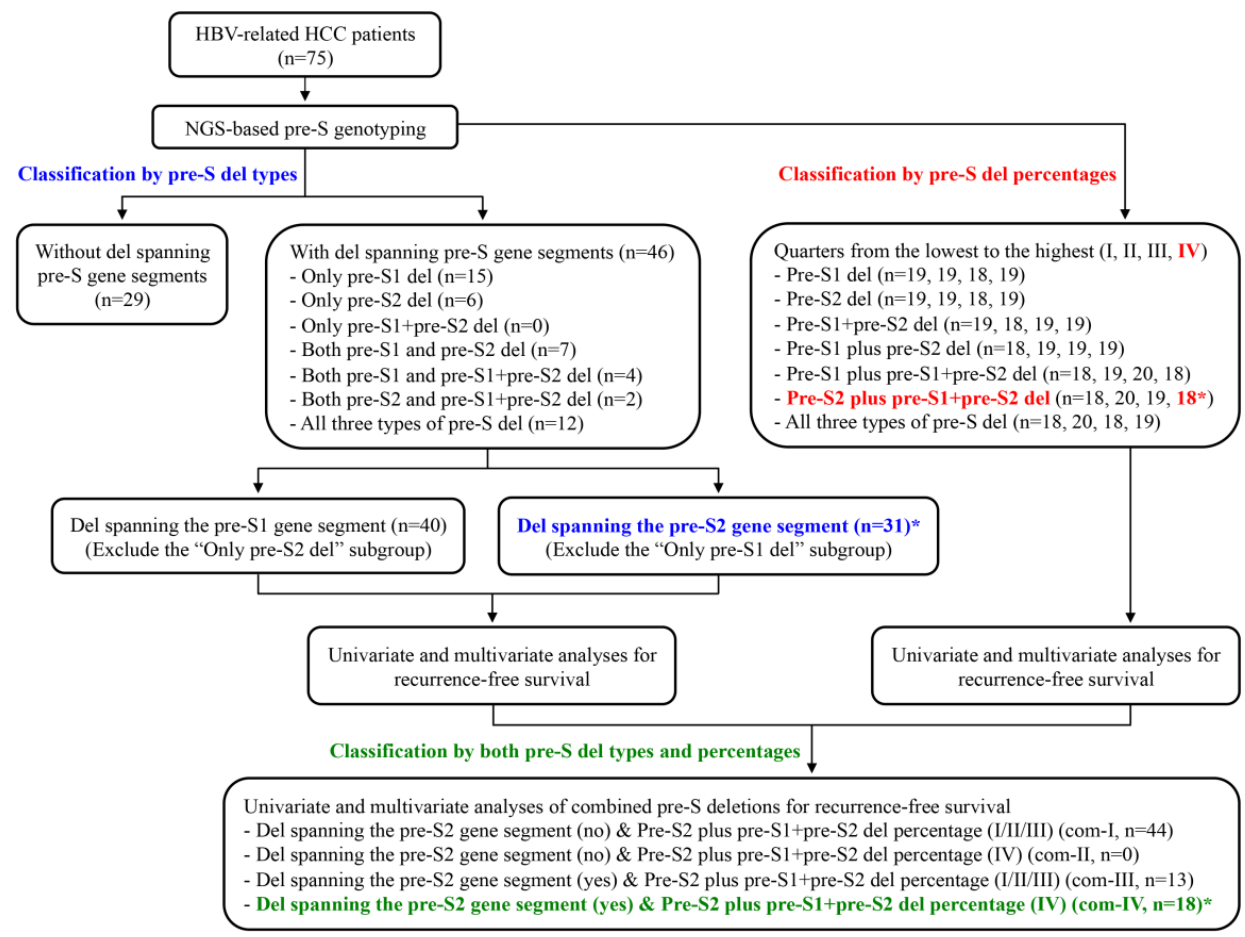

Figure 4. Working scheme of the NGS-based pre-S genotyping platform in the identification of patients at high risk for HCC recurrence after surgical resection. In this study, $75 \mathrm{HBV}$-related HCC patients were analyzed by the NGS-based platform for the detection of pre-S deletions. According to the types of pre-S deletions detected, patients could be classified into the groups without and with deletions spanning the pre-S gene segments. Of the two groups, the latter could be further divided into seven subgroups based on the presence of only pre-S1 deletions, only pre-S2 deletions, only pre-S1 + pre-S2 deletions, both pre-S1 and pre-S2 deletions, both pre-S1 and pre-S1 + pre-S2 deletions, both pre-S2 and pre-S1 + pre-S2 deletions, and all three types of pre-S deletions, respectively. Alternatively, the groups with deletions spanning pre-S gene segments could also be divided into two subgroups, based on the coverage of deletions on either the pre-S1 or pre-S2 gene segment. In addition, patients could be also classified into seven groups according to the percentages of pre-S1 deletions, pre-S2 deletions, pre-S1 + pre-S2 deletions, pre-S1 plus pre-S2 deletions, pre-S1 plus pre-S1 + pre-S2 deletions, pre-S2 plus pre-S1 + pre-S2 deletions, and all three types of pre-S deletions, respectively. Each of the seven groups could be further divided into quarters based on the percentages from the lowest to the highest (designated I to IV, respectively). By univariate and multivariate analyses, either the presence of deletions spanning the pre-S2 gene segment or the highest percentage of pre-S2 plus pre-S1 + pre-S2 deletions was identified as an independent prognostic factor for HCC recurrence after surgical resection. Furthermore, patients could be classified into four groups according to the absence (no)/presence (yes) of deletions spanning the pre-S2 gene segment and the low (I/II/III)/high (IV) percentage of pre-S2 plus pre-S1 + pre-S2 deletions (designated com-I to com-IV, respectively). Through univariate and multivariate analyses, the presence of deletions spanning the pre-S2 gene segment in combination with the high percentage of pre-S2 plus pre-S1 + pre-S2 deletions was also validated as an independent factor for predicting HCC recurrence after surgical resection. Numbers (n) of patients in each group were indicated in parentheses. The patient groups at high risk for HCC recurrence were highlighted with asterisks and different colors according to the classification based on the pre-S deletion types (blue), percentages (red), and both types and percentages (green). Abbreviations: del, deletion; com, combined. 


\section{Conclusions}

In this study, we demonstrated the NGS-based quantitative detection of pre-S mutants in plasma as a powerful approach for identifying the patients at high risk for HBV-related HCC recurrence after surgical resection. The presence of deletions spanning the pre-S2 gene segment and the high percentage of pre-S2 plus pre-S1 + pre-S2 deletions, either alone or in combination, represents a promising noninvasive biomarker for predicting HCC recurrence in patients undergoing surgical resection.

Supplementary Materials: The following are available online at http://www.mdpi.com/1999-4915/12/8/796/s1, Figure S1: Kaplan-Meier curves of OS and RFS differences in the 75 HBV-related HCC patients after surgical resection, Figure S2: Kaplan-Meier curves of OS differences in the $75 \mathrm{HBV}$-related HCC patients after surgical resection, Table S1: List of the pre-S genotyping results by TA cloning- and NGS-based analyses in 75 HBV-related HCC patients, Table S2: Univariate and multivariate analyses of pre-S deletion type for overall survival in 75 HBV-related HCC patients, Table S3: Univariate and multivariate analyses of pre-S deletion percentage for overall survival in 75 HBV-related HCC patients, Table S4: Univariate and multivariate analyses of combined pre-S deletion for overall survival in $75 \mathrm{HBV}$-related HCC patients.

Author Contributions: Conceptualization, C.-F.T., I.-J.S., and L.-B.J.; Formal analysis, T.-C.L. and H.-Y.H.; Funding acquisition, C.-F.T. and L.-B.J.; Investigation, C.-F.T., T.-C.L., H.-Y.H., J.-H.L., and W.-S.C.; Methodology, C.-F.T., T.-C.L., H.-Y.H., W.-C.S., H.-C.W., and C.-Y.P.; Supervision, C.-F.T., I.-J.S., and L.-B.J.; Visualization, C.-F.T., J.-H.L., and W.-S.C.; Writing-original draft, C.-F.T.; Writing-review \& editing, C.-F.T. All authors have read and agreed to the published version of the manuscript.

Funding: This work was supported by the China Medical University Hospital, Taichung, Taiwan (grant numbers DMR-107-034) and the Ministry of Science and Technology, Taipei, Taiwan (grant numbers MOST 107-2320-B-039-053).

Conflicts of Interest: The authors declare no conflict of interest.

\section{References}

1. Llovet, J.M.; Zucman-Rossi, J.; Pikarsky, E.; Sangro, B.; Schwartz, M.; Sherman, M.; Gores, G. Hepatocellular carcinoma. Nat. Rev. Dis. Prim. 2016, 2, 16019. [CrossRef] [PubMed]

2. Venook, A.P.; Papandreou, C.; Furuse, J.; De Guevara, L.L. The Incidence and Epidemiology of Hepatocellular Carcinoma: A Global and Regional Perspective. Oncologist 2010, 15, 5-13. [CrossRef] [PubMed]

3. Cheng, K.-C.; Lin, W.-Y.; Liu, C.-S.; Lin, C.-C.; Lai, H.-C.; Lai, S.-W. Association of different types of liver disease with demographic and clinical factors. Biomedicine 2016, 6, 16. [CrossRef] [PubMed]

4. Llovet, J.M.; Bruix, J. Novel advancements in the management of hepatocellular carcinoma in 2008. J. Hepatol. 2008, 48, S20-S37. [CrossRef]

5. Wall, W.J.; Marotta, P.J. Surgery and transplantation for hepatocellular cancer. Liver Transplant. 2000, 6, s16-s22. [CrossRef] [PubMed]

6. Alsowmely, A.M.; Hodgson, H.J. Non-surgical treatment of hepatocellular carcinoma. Aliment. Pharmacol. Ther. 2002, 16, 1-15. [CrossRef]

7. Llovet, J.M.; Ricci, S.; Mazzaferro, V.M.; Hilgard, P.; Gane, E.; Blanc, J.-F.; De Oliveira, A.C.; Santoro, A.; Raoul, J.L.; Forner, A.; et al. Sorafenib in Advanced Hepatocellular Carcinoma. N. Engl. J. Med. 2008, 359, 378-390. [CrossRef]

8. Marín-Hargreaves, G.; Azoulay, D.; Bismuth, H. Hepatocellular carcinoma: Surgical indications and results. Crit. Rev. Oncol. 2003, 47, 13-27. [CrossRef]

9. Poon, R.T.-P.; Fan, S.-T.; Wong, J. Risk Factors, Prevention, and Management of Postoperative Recurrence After Resection of Hepatocellular Carcinoma. Ann. Surg. 2000, 232, 10-24. [CrossRef]

10. Poon, R.T.-P.; Fan, S.-T.; Lo, C.-M.; Liu, C.-L.; Wong, J. Intrahepatic Recurrence After Curative Resection of Hepatocellular Carcinoma. Ann. Surg. 1999, 229, 216-222. [CrossRef]

11. Beasley, R.; Hwang, L.-Y. Hepatocellular Carcinoma and Hepatitis B Virus. Semin. Liver Dis. 1984, 4, $113-121$. [CrossRef] [PubMed]

12. Bosetti, C.; Turati, F.; La Vecchia, C. Hepatocellular carcinoma epidemiology. Best Pr. Res. Clin. Gastroenterol. 2014, 28, 753-770. [CrossRef] [PubMed]

13. Su, I.-J.; Wang, H.-C.; Wu, H.-J.; Huang, W.-Y. Ground glass hepatocytes contain pre-S mutants and represent preneoplastic lesions in chronic hepatitis B virus infection. J. Gastroenterol. Hepatol. 2008, 23, 1169-1174. [CrossRef] [PubMed] 
14. Fan, Y.; Lu, C.; Chang, Y.; Chang, T.; Lin, P.; Lei, H.; Su, I. Identification of a pre-S2 mutant in hepatocytes expressing a novel marginal pattern of surface antigen in advanced diseases of chronic hepatitis $B$ virus infection. J. Gastroenterol. Hepatol. 2000, 15, 519-528. [CrossRef]

15. Wang, H.-C.; Wu, H.-J.; Chen, C.-F.; Fausto, N.; Lei, H.-Y.; Su, I.-J. Different Types of Ground Glass Hepatocytes in Chronic Hepatitis B Virus Infection Contain Specific Pre-S Mutants that May Induce Endoplasmic Reticulum Stress. Am. J. Pathol. 2003, 163, 2441-2449. [CrossRef]

16. Teng, C.-F.; Wu, H.-J.; Shyu, W.-C.; Jeng, L.-B.; Su, I.-J. Pre-S2 Mutant-Induced Mammalian Target of Rapamycin Signal Pathways as Potential Therapeutic Targets for Hepatitis B Virus-Associated Hepatocellular Carcinoma. Cell Transplant. 2017, 26, 429-438. [CrossRef]

17. Teng, Y.-C.; Neo, J.C.; Wu, J.-C.; Chen, Y.-F.; Kao, C.-H.; Tsai, T.-F. Expression of a hepatitis B virus pre-S2 deletion mutant in the liver results in hepatomegaly and hepatocellular carcinoma in mice. J. Pathol. 2017, 241, 463-474. [CrossRef]

18. Shen, F.-C.; Su, I.-J.; Wu, H.-J.; Hsieh, Y.-H.; Yao, W.-J.; Young, K.-C.; Chang, T.C.; Hsieh, H.-C.; Tsai, H.-N.; Huang, W.-H. A pre-S gene chip to detect pre-S deletions in hepatitis B virus large surface antigen as a predictive marker for hepatoma risk in chronic hepatitis B virus carriers. J. Biomed. Sci. 2009, 16, 84. [CrossRef]

19. Chen, C.; Hung, C.; Chen, W.J.; Hu, T.; Wang, J.; Wang, J.; Lu, S.-N.; Changchien, C. Pre-S Deletion and Complex Mutations of Hepatitis B Virus Related to Advanced Liver Disease in HBeAg-Negative Patients. Gastroenterology 2007, 133, 1466-1474. [CrossRef]

20. Sinn, D.H.; Choi, M.S.; Gwak, G.-Y.; Paik, Y.H.; Lee, J.H.; Koh, K.C.; Paik, S.W.; Yoo, B.C. Pre-S Mutation Is a Significant Risk Factor for Hepatocellular Carcinoma Development: A Long-Term Retrospective Cohort Study. Dig. Dis. Sci. 2012, 58, 751-758. [CrossRef]

21. Fan, Y.; Lu, C.-C.; Chen, W.; Yao, W.-J.; Wang, H.; Chang, T.; Lei, H.-Y.; Shiau, A.-L.; Su, I. Prevalence and significance of hepatitis $\mathrm{B}$ virus (HBV) pre-S mutants in serum and liver at different replicative stages of chronic HBV infection. Hepatology 2001, 33, 277-286. [CrossRef] [PubMed]

22. Tsai, H.-W.; Lin, Y.-J.; Lin, P.-W.; Wu, H.-J.; Hsu, K.-H.; Yen, C.-J.; Chan, S.-H.; Huang, W.-H.; Su, I.-J. A clustered ground-glass hepatocyte pattern represents a new prognostic marker for the recurrence of hepatocellular carcinoma after surgery. Cancer 2011, 117, 2951-2960. [CrossRef] [PubMed]

23. Tsai, H.-W.; Lin, Y.-J.; Wu, H.-C.; Chang, T.-T.; Wu, I.-C.; Cheng, P.-N.; Yen, C.-J.; Chan, S.-H.; Huang, W.; $\mathrm{Su}, \mathrm{I}$.-J. Resistance of ground glass hepatocytes to oral antivirals in chronic hepatitis B patients and implication for the development of hepatocellular carcinoma. Oncotarget 2016, 7, 27724-27734. [CrossRef] [PubMed]

24. Yen, C.-J.; Ai, Y.-L.; Tsai, H.-W.; Chan, S.-H.; Yen, C.-S.; Cheng, K.-H.; Lee, Y.-P.; Kao, C.-W.; Wang, Y.-C.; Chen, Y.-L.; et al. Hepatitis B virus surface gene pre-S2 mutant as a high-risk serum marker for hepatoma recurrence after curative hepatic resection. Hepatology 2018, 68, 815-826. [CrossRef] [PubMed]

25. Teng, C.-F.; Huang, H.-Y.; Li, T.-C.; Shyu, W.-C.; Wu, H.-J.; Lin, C.-Y.; Su, I.-J.; Jeng, L.-B. A Next-Generation Sequencing-Based Platform for Quantitative Detection of Hepatitis B Virus Pre-S Mutants in Plasma of Hepatocellular Carcinoma Patients. Sci. Rep. 2018, 8, 14816. [CrossRef]

26. Teng, C.-F.; Tsai, H.-W.; Li, T.-C.; Wang, T.; Wang, J.; Shyu, W.-C.; Wu, H.-C.; Su, I.-J.; Jeng, L.-B. Detection of hepatitis $\mathrm{B}$ virus pre-S mutants in plasma by a next-generation sequencing-based platform determines their patterns in liver tissues. PLoS ONE 2020, 15, e0234773. [CrossRef]

27. Lee, S.C.; Tan, H.T.; Chung, M.C.M. Prognostic biomarkers for prediction of recurrence of hepatocellular carcinoma: Current status and future prospects. World J. Gastroenterol. 2014, 20, 3112-3124. [CrossRef]

28. Zulehner, G.; Mikula, M.; Schneller, R.; Van Zijl, F.; Huber, H.; Sieghart, W.; Grasl-Kraupp, B.; Waldhör, T.; Peck-Radosavljevic, M.; Beug, H.; et al. Nuclear $\beta$-Catenin Induces an Early Liver Progenitor Phenotype in Hepatocellular Carcinoma and Promotes Tumor Recurrence. Am. J. Pathol. 2010, 176, 472-481. [CrossRef]

29. Yin, X.; Li, Y.-W.; Jin, J.-J.; Zhou, Y.; Ren, Z.-G.; Qiu, S.-J.; Zhang, B.-H. The clinical and prognostic implications of pluripotent stem cell gene expression in hepatocellular carcinoma. Oncol. Lett. 2013, 5, 1155-1162. [CrossRef]

30. Hu, T.; Wang, C.-C.; Huang, C.-C.; Chen, C.-L.; Hung, C.-H.; Chen, C.-H.; Wang, J.-H.; Lu, S.-N.; Lee, C.-M.; Changchien, C.-S.; et al. Down-regulation of tumor suppressor gene PTEN, overexpression of p53, plus high proliferating cell nuclear antigen index predict poor patient outcome of hepatocellular carcinoma after resection. Oncol. Rep. 2007, 18, 1417-1426. [CrossRef] 
31. Yu, S.J.; Kim, Y.J. Hepatitis B viral load affects prognosis of hepatocellular carcinoma. World J. Gastroenterol. 2014, 20, 12039-12044. [CrossRef] [PubMed]

32. Yang, T.; Lu, J.-H.; Zhai, J.; Lin, C.; Yang, G.-S.; Zhao, R.-H.; Shen, F.; Wu, M.-C. High viral load is associated with poor overall and recurrence-free survival of hepatitis B virus-related hepatocellular carcinoma after curative resection: A prospective cohort study. Eur. J. Surg. Oncol. (EJSO) 2012, 38, 683-691. [CrossRef] [PubMed]

33. Sohn, W.; Paik, Y.-H.; Kim, J.M.; Kwon, A.C.H.D.; Joh, J.-W.; Cho, J.Y.; Gwak, G.-Y.; Choi, M.S.; Lee, J.H.; Koh, K.C.; et al. HBV DNA and HBsAg Levels as Risk Predictors of Early and Late Recurrence after Curative Resection of HBV-related Hepatocellular Carcinoma. Ann. Surg. Oncol. 2014, 21, 2429-2435. [CrossRef] [PubMed]

34. Wong, J.S.-W.; Wong, G.L.-H.; Tsoi, K.K.-F.; Wong, V.W.-S.; Cheung, S.Y.-S.; Chong, C.-N.; Lee, K.-F.; Lai, P.B.-S.; Chan, H.L.Y. Meta-analysis: The efficacy of anti-viral therapy in prevention of recurrence after curative treatment of chronic hepatitis B-related hepatocellular carcinoma. Aliment. Pharmacol. Ther. 2011, 33, 1104-1112. [CrossRef]

35. Miao, R.-Y.; Zhao, H.-T.; Yang, H.-Y.; Mao, Y.-L.; Lü, X.; Zhao, Y.; Liu, C.-N.; Zhong, S.-X.; Sang, X.-T.; Huang, J.-F. Postoperative adjuvant antiviral therapy for hepatitis B/C virus-related hepatocellular carcinoma: A meta-analysis. World J. Gastroenterol. 2010, 16, 2931-2942. [CrossRef]

36. Xu, M.; Zhou, Z.; Xu, R.; Lin, N.; Lin, N.; Zhong, Y. Antiviral therapy predicts the outcomes following resection of hepatocellular carcinoma in patients negative for HBV DNA: A propensity score matching analysis. World J. Surg. Oncol. 2019, 17, 45. [CrossRef]

37. Morikawa, K.; Suda, G.; Sakamoto, N. Viral life cycle of hepatitis B virus: Host factors and druggable targets. Hepatol. Res. 2016, 46, 871-877. [CrossRef]

38. Jilbert, A.R.; Reaiche, G.Y.; Clouston, A.; Test, S. Hepatitis B Virus. eLS 2011, 26, 386-387. [CrossRef]

39. Hu, J.; Protzer, U.; Siddiqui, A.; Protzer, U. Revisiting Hepatitis B Virus: Challenges of Curative Therapies. J. Virol. 2019, 93. [CrossRef]

40. Levrero, M.; Zucman-Rossi, J. Mechanisms of HBV-induced hepatocellular carcinoma. J. Hepatol. 2016, 64, S84-S101. [CrossRef]

41. Tu, T.; Budzinska, M.A.; Shackel, N.A.; Urban, S. HBV DNA Integration: Molecular Mechanisms and Clinical Implications. Viruses 2017, 9, 75. [CrossRef] [PubMed]

42. Wang, M.; Xi, N.; Ning, Q. Virus-induced hepatocellular carcinoma with special emphasis on HBV. Hepatol. Int. 2017, 11, 171-180. [CrossRef] [PubMed]

43. Sung, W.-K.; Zheng, H.; Li, S.; Chen, R.; Liu, X.; Li, Y.; Lee, N.P.; Lee, W.H.; Ariyaratne, P.N.; Tennakoon, C.; et al. Genome-wide survey of recurrent HBV integration in hepatocellular carcinoma. Nat. Genet. 2012, 44, 765-769. [CrossRef] [PubMed]

44. Tarocchi, M.; Polvani, S.; Marroncini, G.; Galli, A. Molecular mechanism of hepatitis B virus-induced hepatocarcinogenesis. World J. Gastroenterol. 2014, 20, 11630-11640. [CrossRef] [PubMed]

45. Jia, J.; Liang, X.; Chen, S.; Wang, H.; Li, H.; Fang, M.; Bai, X.; Wang, Z.; Wang, M.; Zhu, S.; et al. Next-generation sequencing revealed divergence in deletions of the preS region in the HBV genome between different HBV-related liver diseases. J. Gen. Virol. 2017, 98, 2748-2758. [CrossRef] [PubMed]

(C) 2020 by the authors. Licensee MDPI, Basel, Switzerland. This article is an open access article distributed under the terms and conditions of the Creative Commons Attribution (CC BY) license (http://creativecommons.org/licenses/by/4.0/). 